\title{
O hemograma: importância para a interpretação da biópsia
}

\section{Blood cell analysis: the importance for biopsy interpretation}

Helena Z. W. Grotto

\section{Introdução}

A diversidade de informações que o hemograma pode fornecer, embora em geral bastante inespecíficas, torna esse exame subsidiário um dos mais solicitados nas práticas clínica e cirúrgica. As informações fornecidas pela análise do sangue periférico pretendem responder a duas questões básicas: a medula óssea está produzindo um número suficiente de células maduras de diferentes linhagens? os processos de proliferação, diferenciação e aquisição de funções de cada tipo celular estão se desenvolvendo de maneira adequada em todas as linhagens celulares? Essa perguntas podem ser respondidas pelos parâmetros numéricos fornecidos pelos sistemas hematológicos automatizados e pelo exame morfológico das células à microscopia óptica. Assim, a somatória da análise de: aspectos quantitativos + aspectos morfológicos + conhecimento fisiopatológico dos distúrbios da hematopoiese será de grande auxílio diagnóstico em diversas condições clínicas, servindo de importante subsídio para a observação da medula óssea, podendo ser indicativas de diversos distúrbios medulares.

Durante as últimas décadas observou-se uma grande evolução tecnológica na realização do hemograma, e as técnicas manuais têm sido substituídas por sistemas automatizados que apresentam maior precisão nos resultados e em um menor intervalo de tempo. No final dos anos 50 e início dos anos 60 surgiram no mercado os primeiros contadores de células semiautomáticos e a partir de então os

Professora Associada. Docente do Departamento de Patologia Clínica da Faculdade de Ciências Médicas da Unicamp - Campinas-SP.

Correspondência: Helena Zerlotti Wolf Grotto

Departamento de Patologia Clínica da Faculdade de Ciências Médicas - Unicamp - Campinas-SP.

Caixa Postal 6111.

13083-970 - Campinas-SP - Brasil

E-mail: grotto@fcm.unicamp.br

Doi:10.1590/S1516-84842009005000045 
avanços na engenharia eletrônica permitiram uma crescente automatização do processo. As contagens de plaquetas foram incorporadas aos sistemas automatizados na década de 70 , fornecendo resultados mais confiáveis do que as contagens manuais em câmara. E, finalmente, a contagem diferencial dos leucócitos teve sua grande evolução a partir dos anos 80 , quando novas tecnologias, como a citometria de fluxo e a citoquímica, foram agregadas aos sistemas de identificação das células sanguíneas. Essas inovações mudaram a rotina dos laboratórios, tornando-os mais eficientes e ágeis, além de apresentarem uma melhor qualidade nos resultados. Adicionalmente, novos parâmetros laboratoriais continuamente são implementados com o objetivo de ampliar as informações fornecidas pelo hemograma e, assim, auxiliar no diagnóstico de uma gama considerável de patologias. ${ }^{1}$

Um estudo realizado em $2002^{2}$ com o objetivo de identificar os componentes do hemograma considerados úteis na prática clínica revelou resultados interessantes. Somente 4 dos 11 parâmetros rotineiramente fornecidos foram selecionados como úteis e frequentemente utilizados por mais de 90\% dos profissionais inquiridos: dosagem de hemoglobina $(\mathrm{Hb})$, determinação do hematócrito (Ht), contagens de plaquetas e de leucócitos. Alguns ítens mais recentemente propostos foram reconhecidos pelos profissionais com menos de 10 anos de atividade clínica, diferentemente do observado quando médicos com mais tempo de vida profissional foram questionados. Embora $50 \%$ dos médicos entrevistados desempenhassem suas funções em tempo integral dentro de instituições acadêmicas e outros 34\% em tempo parcial nas universidades, alguns desvios de interpretação, como a preferência da análise da contagem diferencial de leucócitos em números percentuais e não absolutos, ou o desuso das informações referentes às alterações morfológicas das células foram muito comuns. Esses dados provenientes da pesquisa no Hospital Universitário de Cleveland (Estados Unidos) são preocupantes e, provavelmente, coincidentes que os que seriam obtidos em diversos outros locais, inclusive no Brasil, se tal pesquisa fosse aplicada.

De um lado temos as empresas investindo em tecnologia e lançando continuamente no mercado uma série de novos parâmetros e índices no hemograma; e de outro lado o despreparo do requisitante do exame no reconhecimento desses novos indicadores, aliado à falta de visão crítica sobre as reais vantagens ou limitações dos mesmos. Uma divulgação prévia por parte dos realizadores dos exames sobre o significado de cada um dos novos parâmetros lançados ou a adequação na maneira de reportar os resultados poderiam minimizar as falhas ou ausência de interpretação de vários dados fornecidos pelo hemograma.

Pretendemos apresentar, de forma resumida, algumas considerações a respeito de aspectos relacionados a essas inovações no hemograma que têm sido propostas como auxiliares no diagnóstico de algumas condições clínicas.

\section{Na série vermelha}

Dentre os índices hematimétricos, o VCM (volume corpuscular médio) ainda é o mais largamento utilizado na avaliação das anemias, associado à análise das alterações morfológicas das hemácias, que também pode fornecer subsídios interessantes no reconhecimento de diversos tipos de anemia. Adicionalmente, uma medida quantitativa da anisocitose, conhecida como RDW (red cell distribution width), tem algumas aplicações interessantes. O RDW é obtido a partir do histograma de distribuição das hemácias de acordo com o volume das células e é reportado em porcentagem, com valores de normalidade entre $11 \%$ e $16 \%$, dependendo do equipamento utilizado. ${ }^{3,4}$ Valores aumentados de RDW falam a favor de uma população eritrocitária heterogênea, formada por células de diversos tamanhos. Sua principal utilidade seria numa primeira diferenciação entre a anemia ferropriva e a beta talassemia heterozigótica. A acurácia desse parâmetro na distinção desses dois tipos de anemia microcítica varia entre diversos autores., ${ }^{5,6} \mathrm{O}$ que se preconiza é que o valor de RDW seja analisado junto com outros

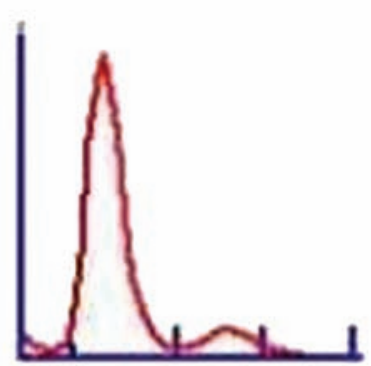

Normal

$\mathrm{RDW}=14 \%$

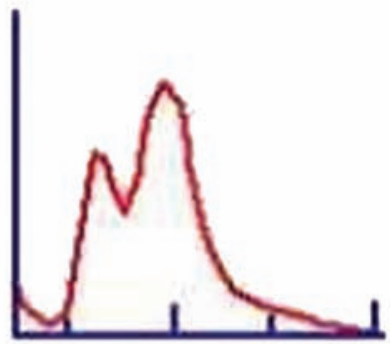

Dupla população

$\mathrm{RDW}=22 \%$

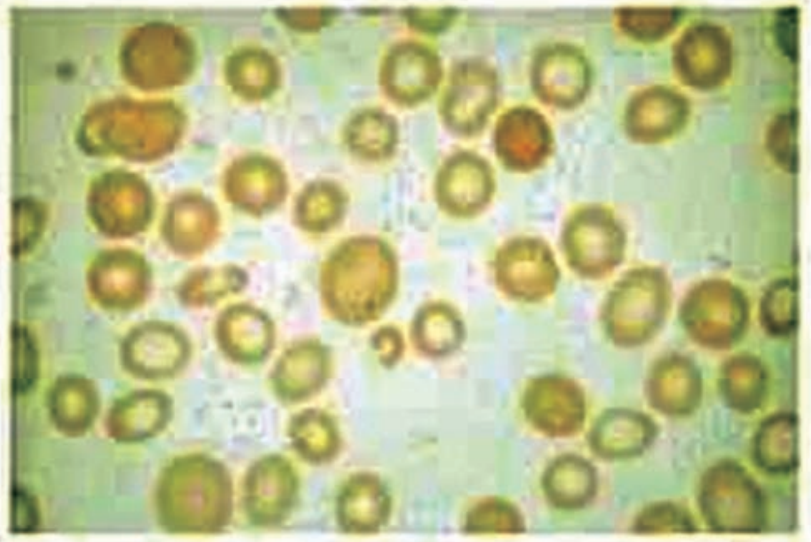

Figura 1. Curva de distribuição das hemácias de acordo com o volume, em condições normal (à esquerda) e patológica (à direita). Microscopia de sangue periférico mostrando dupla população eritrocitária 
Quadro 1. Classificação das anemias de acordo com a capacidade de regeneração medular

\begin{tabular}{|c|c|}
\hline $\begin{array}{l}\text { Anemias hiporegenerativas } \\
\quad\left(\text { RTC }<50 \times 10^{9} /\right)\end{array}$ & $\begin{array}{l}\text { Anemias regenerativas } \\
\left.\qquad \mathrm{RTC}>100 \times 10^{9} \mathrm{l}\right)\end{array}$ \\
\hline $\begin{array}{l}\text { Falência medular por defeito nas células precursoras: } \\
\text { anemia aplástica, síndrome mielodisplásica, aplasia pura } \\
\text { da célula vermelha }\end{array}$ & $\begin{array}{l}\text { Por aumento de destruição: anemias hemolíticas } \\
\text { - imunes, associadas ou não a outros processos auto-imunes ou } \\
\text { doenças linfoproliferativas, estados infecciosos, uso de drogas }\end{array}$ \\
\hline $\begin{array}{l}\text { Estados carenciais: deficiência de ferro, vitamina B12 e } \\
\text { ácido fólico } \\
\text { Infiltração medular por fibrose (mielofibrose), } \\
\text { neoplasias hematológicas, tumores sólidos } \\
\text { Consequente a estados inflamatórios }\end{array}$ & $\begin{array}{l}\text { não-imunes: } \\
\text { - congênitas: hemoglobinopatias (doenças falciformes e talassemias), } \\
\text { enzimopatias (deficiências de glicose } 6 \text { - fosfato desidrogenase e } \\
\text { piruvato quinase), Hb instável, esferocitose hereditária. } \\
\text { - adquiridas: hemoglobinúrua paroxística noturna, microangiopática, } \\
\text { hiperesplenism }\end{array}$ \\
\hline Falência renal com diminuição da produção de EPO & Por perda de volume sanguíneo: anemias hemorrágicas \\
\hline
\end{tabular}

(Modificado de Lambert \& Beris 2006) ${ }^{9}$

parâmetros do hemograma. De maneira geral, anemias microcíticas com número de hemácias abaixo de $5 \times 10^{9} / \mathrm{l}$ e RDW elevado são mais favoráveis ao diagnóstico de anemia ferropriva, enquanto anemias microcíticas com número de hemácias acima de $5 \times 10^{9} / \mathrm{l}$ e RDW normal ou pouco elevado deveriam ser encaminhadas para a investigação da presença de traço talassêmico. A análise da curva de distribuição de hemácias de acordo com o seu volume, que é a base de cálculo do RDW, também pode indicar, por exemplo, a presença de dupla população eritrocitária, como pode ocorrer na anemia sideroblástica e em pacientes transfundidos. O mesmo ocorre durante o tratamento de reposição de ferro, quando circulam hemácias de diferentes idades e formadas em diversas condições de suprimento de ferro (Figura 1).

A introdução da contagem automatizada dos reticulócitos e o uso de marcadores fluorescentes restabeleceram o valor desse importante indicador da atividade eritropoética medular. A associação da classificação morfológica das anemias a partir dos índices hematimétricos com a caracterização da anemia de acordo com a resposta medular (Quadro 1) auxilia substancialmente no diagnóstico diferencial e na provável etiologia da anemia. Além da contagem dos reticulócitos, novos parâmetros relacionados ao grau de maturidade dessas células têm sido investigados em diversas condições clínicas onde se pretende estimar a capacidade regenerativa da medula após procedimentos terapêuticos como quimioterapia ou transplante de células precursoras, ${ }^{7}$ ou mesmo como auxiliar diagnóstico entre diversos tipos de anemia. ${ }^{8}$ A nomenclatura para esse índice varia de acordo com o equipamento hematológico utilizado, que pode ser reportado como: RMI (reticulocyte maturity index), IRF (immature reticulocyte fraction) e MFI (mean fluorescent index). ${ }^{1}$

Mais recentemente, o conteúdo de hemoglobina dos reticulócitos tem sido proposto como uma ferramenta interessante no diagnóstico precoce da deficiência de ferro, principalmente em pacientes renais, onde a avaliação do estado de ferro é particularmente importante para monitorar a resposta à terapêutica com eritropoetina recombinante. ${ }^{10,11,12}$ Dependendo do equipamento utilizado, o conteúdo de hemoglobina do reticulócito é denominado $\mathrm{CHr}$ (conteúdo de hemoglobina do reticulócito), MRV (volume reticulocitário médio) ou RetHe (equivalente de hemoglobina dos reticulócitos). Vale ressaltar que, em outras condições que cursam com déficit de hemoglobinizacão, como a talassemia beta heterozigótica, o conteúdo de hemoglobina dos reticulócitos estará igualmente reduzido. ${ }^{1}$

\section{Na série leucocitária}

O grande avanço tecnológico na análise da série branca foi a possibilidade da contagem diferencial dos leucócitos ser automatizada, fornecendo resultado rápido e preciso. As células são identificadas e quantificadas por diferentes metodologias, incluindo impedância, radiofrequência e citoquímica. Além das células maduras morfologicamente normais, linfócitos atípicos, granulócitos imaturos e células blásticas podem ser detectados e mesmo quantificados por determinados sistemas automatizados. A sensibilidade e a precisão nessa detecção dependem da metodologia utilizada e devem ser avaliadas cuidadosamente. Por isso, cada laboratório deve estabelecer os seus critérios de revisão das lâminas de acordo com as características do sistema utilizado. A identificação dos granulócitos imaturos é de especial interesse na rotina clínica porque poderia indicar a presença de um quadro infeccioso agudo. Os equipamentos existentes no mercado atualmente ainda são limitados no que se refere à contagem de bastonetes, mas são bastante sensíveis quando da presença de células da linhagem granulocítica anteriores aos bastonetes, o que caracteriza o "desvio à esquerda" comumente observado nas infecções por bactérias gram-positivas. ${ }^{1}$ A quantificação de linfócitos atípicos e células blásticas não apresenta resultados tão precisos como os obtidos na detecção das células maduras normais, mas a emissão de alarmes sugestivos das mesmas deve servir de orientação para que o material seja revisado à microscopia. Além da contagem diferencial de leucócitos é possível 
determinar o número de eritroblastos nucleados, importantes na sinalização de um possível quadro hemolítico, hematopoiese extramedular ou stress hematopoético, como observado em infecções graves, hipóxia ou hemorragia aguda. ${ }^{13}$ Os métodos automatizados fornecem resultados muito mais precisos do que as contagens manuais, uma vez que o número de eventos contados é muito superior aos observados à microscopia, o que reduz significativamente 0 erro estatístico. Além disso, alguns equipamentos já fazem a correção pelo número total de leucócitos, já que eritrócitos nucleados são contados inicialmente como leucócitos.

Uma outra possibilidade em termos de identificação morfológica das células foi recentemente lançada no mercado e é constituída por um sistema automatizado de análise de células, composto por um microscópio com três objetivas de diferentes aumentos, uma câmera e um sistema computacional com um software que capta e classifica as células a partir de um banco de dados preexistente, que pode ser modificado ou acrescido pelo usuário. Em 2007 foi publicado um estudo em que amostras de sangue de 84 pacientes com doenças hematológicas malignas foram analisadas por um sistema conforme descrito acima, tendo como referência a análise microscópica usual. Segundo os autores, a eficiência do método foi de $95 \%$. Todas as amostras que apresentavam células blásticas foram identificadas, embora o número de células fosse subestimado em alguns casos, em especial na leucemia linfóide aguda. ${ }^{14} \mathrm{~A}$ principal vantagem da utilização dessa tecnologia é que possibilita uma maior agilização da rotina laboratorial, triando as amostras normais e fornecendo dados importantes para o examinador, já que auxilia na identificação das alterações morfológicas das células. Uma outra vantagem é a possibilidade de comunicação entre especialistas, uma vez que as imagens podem ser transmitidas eletronicamente, o que permite a troca de informações entre os observadores. A desvantagem principal é o preço do sistema, ainda inviável para a maioria dos laboratórios.

\section{Na série plaquetária}

Impedância elétrica, sistema óptico, radiofrequência e uso de marcadores imunológicos específicos para plaquetas são metodologias empregadas nos diversos sistemas automatizados, visando melhorar a acurácia e diminuir a ocorrência de interferentes nas contagens de plaquetas. A detecção precisa dos valores das plaquetas, especialmente no diagnóstico das plaquetopenias, é de suma importância na prática clínica e cirúrgica, no monitoramento das quimioterapias e procedimentos de transplante, entre diversas outras situações. De maneira geral, os resultados têm sido bastante promissores. Um estudo avaliando a contagem de plaquetas em amostras pediátricas, tendo como referência o método imunológico usando CD61 como marcador das plaquetas, mostrou uma boa acurácia para a contagem por impedância e valores médios ligeiramente menores para as contagens feitas pelos métodos ótico e manual. Em geral, a precisão foi menor nas amostras com menos do que $50 \mathrm{x}$ $10^{9} / \mathrm{L}$ e naquelas provenientes de neonatos. ${ }^{15}$ Além da quantificação das plaquetas, parâmetros relacionados ao tamanho (VPM - volume plaquetário médio) e o PDW análogo ao RDW para os eritrócitos, podem fornecer informações interessantes sobre a atividade trombopoética, ${ }^{16}$ ou como tem sido avaliado após procedimentos de transplante. ${ }^{17}$ É sugerido que as trombocitopenias de origem medular cursam com VPM reduzido, enquanto as resultantes de destruição periférica apresentam valores mais elevados de VPM, refletindo a liberação precoce na circulação de plaquetas mais jovens e de maior volume. ${ }^{18} \mathrm{O}$ grau de imaturidade das plaquetas, reportado como IPF (immature platelet fraction) também pode ser avaliado. Corresponde à fração de plaquetas reticuladas que contêm RNA citoplasmático e que permanecem na circulação por 24 a 36 horas, quando, então, o RNA é degradado, o volume é reduzido e a plaqueta atinge a sua maturidade. Tem sido investigada como auxiliar na detecção precoce de recuperação medular após transplante de medula óssea, quimio ou radioterapia, além de indicativa da atividade megacariocítica, como o VPM. ${ }^{19}$ Recentemente foi publicado um estudo com 51 pacientes com síndrome mielodisplásica (SMD), que mostrou que uma parte desses indivíduos apresentava uma discrepância entre altos valores de IPF e o grau de trombocitopenia. Em geral, quanto mais grave a plaquetopenia maiores os valores de IPF. Doze pacientes com SMD mostraram contagens de plaquetas superiores a $50 \times 10 \% / \mathrm{L}$ com IPF superior a $10 \%$. Todos esses pacientes apresentaram alterações cromossômicas incluindo anormalidades no cromossoma 7, acompanhadas de sinais de dismegacariocitopoiese. Naqueles com valores de IPF superiores a $20 \%$, a sobrevida foi menor quando comparada aos demais pacientes. Os 39 pacientes restantes não mostraram anormalidade no cromossoma 7, o que levou os autores a sugerirem que contagens aberrantes de IPF poderiam ser indicadoras de distrombopoiese e de mal prognóstico na SMD. ${ }^{20}$

Concluindo, o hemograma, embora tenha um poder diagnóstico limitado, nas mãos de um clínico que conheça as funções celulares e as bases fisiopatológicas das doenças pode ser uma ferramenta importante para a avaliação de diversas situações, como no diagnóstico e evolução de doenças hematológicas, detecção de quadros infecciosos e no monitoramento terapêutico. Novos parâmetros laboratoriais obtidos de sistemas automatizados podem ser auxiliares na análise do sangue e da medula óssea, mas devem ser utilizados com cautela. Vale lembrar que a microscopia ainda é fundamental para a identificação de várias anormalidades na hematopoiese. A associação dos dados referentes a aspectos quantitativos, aspectos morfológicos e conhecimento fisiopatológico dos distúrbios da hematopoiese é importante para um diagnóstico preciso das alterações que acometem o sangue e a medula óssea. 


\begin{abstract}
Examination of blood cells is an essential part of the hematological investigation. The introduction of new physical principles for cell analysis incorporated into automated cell counters has provided new information about blood cells. Data related to both quantification and cell morphology features observed in peripheral blood examinations may be helpful during bone marrow analysis. In this brief review some of these new parameters are presented, such as the red blood cell distribution width (RDW) and indices related to volume, immaturity and hemoglobin content of reticulocytes. The interpretation of graphic displays (histograms of red cells, white cells and platelets) can provide further information that is not available from the assessment of numeric data. Other parameters and platelet indices, such as the mean platelet volume (MPV) and immature platelet fraction (IPF) are introduced, although they are still not standardized and must be used with caution. The quantification of various white blood cell populations present in peripheral blood and the advantages and limitations of automated counts are considered. Although the development of sophisticated automated blood cell analyzers has reduced the number of blood smear examinations, this type of procedure should be encouraged as the smear is an important tool in the diagnosis of several pathologic conditions. Rev. Bras. Hematol. Hemoter. 2009;31(3):178-182.
\end{abstract}

Key words: Blood cell analyzers; reticulocyte indices; platelet parameters; automation.

\section{Referências Bibliográficas}

1. Grotto HZW (ed). Interpretação clínica do Hemograma. São Paulo: Editora Atheneu; 2008.

2. Sandhaus LM, Meyer P. How useful are CBC and reticulocyte reports to clinicians? Am J Clin Pathol. 2002;118(5):787-93.

3. Dixon LR. The complete blood count: physiologic basis and clinical usage. J Perinat Neonatal Nurs. 1997;11(3):1-18.

4. Lewis SM, Bain BJ, Bates I (eds). Practical Haematology, 9th ed. London: Churchill Livingstone; 2001.

5. Green R, King R. A new red cell discriminant incorporating volume dispersion for differentiating iron deficiency anemia from thalassemia minor. Blood Cells. 1989;15(3):481-91.

6. Lima CS, Reis AR, Grotto HZ, Saad ST, Costa FF. Comparison of red cell distribution width and a red cell discriminant function incorporating volume dispersion for distinguishing iron deficiency from beta thalassemia trait in patients with microcytosis. Sao Paulo Med J. 1996;114(5):1265-9.

7. Noronha JF, Lorand-Metze IG, Grotto HZ. Hematopoietic progenitor cells (HPC) and immature reticulocytes evaluations in mobilization process: new parameters measured by conventional blood cell counter. J Clin Lab Anal. 2006;20(4):149-53.

8. Cortellazzi LC, Teixeira SM, Borba R, Gervásio S, Cintra CS, Grotto HZW. Reticulocyte parameters in hemoglobinopathies and iron deficiency anemia. Rev Bras Hematol Hemoter. 2003;25(2):97-102.

9. Lambert J-F, Beris P. Pathophysiology and differential diagnosis of anemia. In: Beaumont C, Beris P, Beuzard Y, Brugnara C. Disorders of iron homeostasis, erythrocytes, erythropoiesis. Genoa, Italy: Forum Service Editore; 2006, cap 3; p. 73-101.
10. Brugnara C, Schiller B, Moran J. Reticulocyte hemoglobin equivalent (Ret $\mathrm{He}$ ) and assessment of iron-deficient states. Clin Lab Haematol. 2006;28(5):303-8.

11. Mast AE, Blinder MA, Dietzen DJ. Reticulocyte hemoglobin content. Am J Hematol. 2008;83(4):307-10.

12. Kim JM, Ihm CH, Kim HJ. Evaluation of reticulocyte haemoglobin content as marker of iron deficiency and predictor of response to intravenous iron in haemodialysis patients. Int J Lab Hematol. 2008;30(1):46-52.

13. Schaefer M \& Rowan RM. The clinical relevance of nucleated red blood celll counts. Sysmex J Intern. 2000;10:59-63.

14. Cornet E, Perol JP, Troussard X. Performance evaluation and relevance of the CellaVision DM96 system in routine analysis and in patients with malignant hematological diseases. Int J Lab Hematol. 2008;30(6):536-42.

15. Felle P, McMahon C, Rooney S, Donnelly P, Ni Chonchubhair F. Platelets in the paediatric population: the influence of age and the limitations of automation. Clin Lab Haematol. 2005;27 (4): 250-7.

16. Abe Y, Wada H, Tomatsu H, Sakaguchi A, Nishioka J, Yabu Y, et al. A simple technique to determine thrombopoiesis level using immature platelet fraction (IPF). Thromb Res. 2006;118(4): 463-9.

17. Takami A, Shibayama M, Orito M, Omote M, Okumura H, Yamashita $\mathrm{T}$, et al. Immature platelet fraction for prediction of platelet engraftment after allogeneic stem cell transplantation. Bone Marrow Transplant. 2007;39(8):501-7.

18. Threatte GA. Usefulness of the mean platelet volume. Clin Lab Med. 1993;13(4):937-50.

19. Buttarello M, Plebani M. Automated blood cell counts: state of the art. State of the art. Am J Clin Pathol. 2008;130(1):104-16.

20. Sugimori N, Kondo Y, Shibayama M, Omote M, Takami A, Sugimori $\mathrm{C}$, et al. Aberrant increase in the immature platelet fraction in patients with myelodysplastic syndrome: a marker of karyotypic abnormalities associated with poor prognosis. Eur J Haematol. 2009;82(1):54-60.

Avaliação: Editor e dois revisores externos

Conflitos de interesse: sem conflitos de interesse

Recebido: 13/10/2008

Aceito: 13/02/2009 